\title{
Comparative Study of Five Different DNA Fingerprint Techniques for Molecular Typing of Streptococcus pneumoniae Strains
}

\author{
PETER W. M. HERMANS, ${ }^{*}{ }^{*}$ MARCEL SLUIJTER, ${ }^{1}$ THEO HOOGENBOEZEM, ${ }^{1}$ HERRE HEERSMA, ${ }^{2}$ \\ ALEX VAN BELKUM, ${ }^{3}$ AND RONALD DE GROOT ${ }^{1}$ \\ Department of Pediatrics ${ }^{1}$ and Department of Clinical Microbiology, ${ }^{3}$ University Hospital Rotterdam, Erasmus \\ University Rotterdam, 3000 DR Rotterdam, and Unit Molecular Microbiology, National Institute of \\ Public Health and Environmental Protection, 3720 BA Bilthoven, ${ }^{2}$ The Netherlands
}

Received 20 December 1994/Returned for modification 27 February 1995/Accepted 20 March 1995

\begin{abstract}
The aim of this study was to identify the strengths and weaknesses of five DNA fingerprint methods for epidemiological typing of Streptococcus pneumoniae. We investigated the usefulness of (i) ribotyping, (ii) BOX fingerprinting with the BOX repetitive sequence of $S$. pneumoniae as a DNA probe, (iii) PCR fingerprinting with a primer homologous to the enterobacterial repetitive intergenic consensus sequence, (iv) pulsed-field gel electrophoresis of large DNA fragments, and (v) restriction fragment end labeling to detect restriction fragment length polymorphism of small DNA fragments. Twenty-eight $S$. pneumoniae strains isolated from the blood and/or cerebrospinal fluid of 21 patients were analyzed. Genetic clustering among the 28 strains was independent of the DNA fingerprint technique used. However, the discriminatory power and the similarity values differed significantly among the individual techniques. BOX fingerprinting, pulsed-field gel electrophoresis, and restriction fragment end labeling provided the highest degree of discriminatory power. Furthermore, the ease with which computerized fingerprint analysis could be conducted also varied significantly among the techniques. Ribotyping, BOX fingerprinting, and restriction fragment end labeling were very suitable techniques for accurate computerized data analysis. Because of their high discriminatory potential and ease of accurate analysis, we conclude that BOX fingerprinting and restriction fragment end labeling are the most suitable techniques to type pneumococcal strains.
\end{abstract}

Infections with Streptococcus pneumoniae are an important cause of morbidity and mortality. The pathogen accounts for most cases of community-acquired pneumonia in children and adults and is a leading cause of meningitis and sepsis. In the Western world, the incidence of pneumococcal meningitis has been estimated at 1.5 cases per 100,000 individuals per year, with an average mortality rate of 30 to $40 \%$. Pneumococcal bacteremia occurs with a frequency of 5 to 10 cases per 100,000 individuals per year (4). The emergence of high-level resistance to penicillin complicates the institution of adequate antimicrobial therapy. In some countries, the prevalence of resistant clinical isolates rose to extremely high levels, up to $70 \%$ in Spain (3) and Hungary (11). The high incidence of pneumococcal infections and the increasing emergence of drugresistant isolates are the major reason for epidemiological surveillance. Phenotypical and genotypical methods have been developed to assist in epidemiological investigations. These methods include serotyping $(9,16,18,19)$, multilocus enzyme electrophoresis (15), penicillin-binding protein typing $(12,13$, $15,21)$ and pneumococcal surface protein A typing (15), and various DNA fingerprint methods such as ribotyping $(1,6,12)$, DNA fingerprinting of the penicillin-binding protein genes $(6$, $13,14,20)$, and pulsed-field gel electrophoresis $(8,21)$. The combined use of molecular typing methods has identified the intercontinental epidemic spread of multiresistant pneumococcal strains $(7,12,13,21)$. In contrast to the clonal epidemic spread of resistant pneumococcal strains, an extensive genetic diversity has been observed among penicillin-resistant pneumococci in South Africa (20) and Kenya (6). The increasing

\footnotetext{
* Corresponding author. Mailing address: Department of Pediatrics, University Hospital Rotterdam, Erasmus University Rotterdam, P.O. Box 1738, 3000 DR Rotterdam, The Netherlands.
}

emergence of penicillin-resistant strains in these African countries is thought to be due to horizontal transfer of altered penicillin-binding protein genes which cause resistance to penicillin (2).

In order to obtain meaningful epidemiological information from DNA fingerprints, a genetic marker must give different fingerprint patterns in epidemiologically unrelated strains but an identical pattern for strains from a common source. For epidemiological investigations, DNA fingerprint markers that reflect an adequate rate of genetic rearrangements over time are needed. A better understanding of the speed of genetic rearrangements affecting individual markers will result in the selective use of those markers which are appropriate for answering a given epidemiological question.

We investigated the usefulness of various DNA fingerprint methods for the study of the molecular epidemiology of infections with $S$. pneumoniae. Twenty-eight clinical isolates of $S$. pneumoniae were analyzed by (i) ribotyping, (ii) $\mathrm{BOX}$ fingerprinting with the BOX repetitive DNA element (10) as a DNA probe, (iii) PCR fingerprinting with a primer homologous to the enterobacterial repetitive intergenic consensus sequence (25), (iv) pulsed-field gel electrophoresis of large DNA restriction fragments, and (v) restriction fragment end labeling, which detects restriction fragment length polymorphism (RFLP) of small DNA fragments (24). The discriminatory powers of and the patterns of the genetic clustering of the pneumococcal isolates determined by the five different DNA typing methods were compared, and the potential of the individual fingerprint methods to type pneumococcal strains was examined.

\section{MATERIALS AND METHODS}

Bacterial strains and growth conditions. Twenty-eight pneumococcal isolates were obtained from the National Reference Center for Bacterial Meningitis (L. 
TABLE 1. DNA fingerprint results for 28 S. pneumoniae strains analyzed by ribotyping, BOX fingerprinting, PCR fingerprinting, pulsed-field gel electrophoresis, DNA end labeling, and serotyping

\begin{tabular}{|c|c|c|c|c|c|c|c|c|}
\hline \multirow[b]{2}{*}{$\begin{array}{l}\text { S. pneumoniae } \\
\text { strain }^{a}\end{array}$} & \multirow[b]{2}{*}{ Lane $^{b}$} & \multicolumn{5}{|c|}{ Strain type ${ }^{c}$} & \multirow[b]{2}{*}{$\begin{array}{l}\text { DNA } \\
\text { type }^{d}\end{array}$} & \multirow{2}{*}{$\begin{array}{l}\text { Sero- } \\
\text { type }\end{array}$} \\
\hline & & $16 \mathrm{~S}$ & BOX $^{e}$ & PCR & PFGE & $\begin{array}{c}\text { End } \\
\text { labeling }\end{array}$ & & \\
\hline 022B & 25 & A & A & A & A & A & 1 & $7 F$ \\
\hline $022 \mathrm{C}$ & 26 & A & A & A & A & A & 1 & $7 \mathrm{~F}$ \\
\hline 019B & 10 & A & B & A & A & A & $\mathbf{1 A}$ & 8 \\
\hline 079B & 24 & A & $\mathrm{C}$ & A & A & A & $1 \mathrm{~B}$ & $7 \mathrm{~F}$ \\
\hline 078B & 15 & A & D & B & B & B & 2 & 4 \\
\hline 181B & 2 & B & E & C & C & C & 3 & $6 \mathrm{~B}$ \\
\hline $181 \mathrm{C}$ & 3 & B & E & C & $\mathrm{C}$ & C & 3 & $6 \mathrm{~B}$ \\
\hline 063B & 21 & B & $\mathrm{F}$ & D & D & D & 4 & $23 \mathrm{~F}$ \\
\hline $063 \mathrm{C}$ & 22 & B & $\mathrm{F}$ & D & D & D & 4 & $23 \mathrm{~F}$ \\
\hline 174B & 11 & $\mathrm{C}$ & G & E & E & E & 5 & $19 \mathrm{~F}$ \\
\hline $187 \mathrm{C}$ & 20 & $\mathrm{C}$ & $\mathrm{H}$ & $\mathrm{F}$ & $\mathrm{F}$ & E & 6 & $18 \mathrm{C}$ \\
\hline $200 \mathrm{C}$ & 4 & $\mathrm{D}$ & D & G & G & $\mathrm{F}$ & 7 & $6 \mathrm{~B}$ \\
\hline $015 \mathrm{C}$ & 9 & $\mathrm{D}$ & I & $\mathrm{H}$ & $\mathrm{H}$ & G & 8 & 8 \\
\hline $241 \mathrm{C}$ & 13 & D & $\mathrm{J}$ & I & I & $\mathrm{H}$ & 9 & $9 \mathrm{~V}$ \\
\hline $353 \mathrm{~B}$ & 14 & $\mathrm{D}$ & K & I & $\mathrm{J}$ & $\mathrm{H}$ & 10 & $9 \mathrm{~V}$ \\
\hline 797B & 16 & $\mathrm{D}$ & $\mathrm{L}$ & $\mathrm{J}$ & K & I & 11 & 4 \\
\hline $797 \mathrm{C}$ & 17 & $\mathrm{D}$ & $\mathrm{L}$ & $\mathrm{J}$ & $\mathrm{K}$ & I & 11 & 4 \\
\hline $242 B$ & 18 & $\mathrm{D}$ & $\mathrm{K}$ & K & $\mathrm{J}$ & $\mathrm{H}$ & 12 & $18 \mathrm{C}$ \\
\hline $242 \mathrm{C}$ & 19 & $\mathrm{D}$ & M & $\mathrm{L}$ & $\mathrm{J}$ & $\mathrm{J}$ & 13 & $18 \mathrm{C}$ \\
\hline 021B & 27 & $\mathrm{D}$ & $\mathrm{N}$ & M & $\_^{f}$ & K & 14 & 14 \\
\hline $064 \mathrm{C}$ & 28 & $\mathrm{D}$ & $\mathrm{N}$ & M & $\mathrm{L}$ & K & 14 & 14 \\
\hline $189 \mathrm{C}$ & 12 & $\mathrm{D}$ & $\mathrm{O}$ & B & M & $\mathrm{L}$ & 15 & $9 \mathrm{~F}$ \\
\hline $310 \mathrm{~B}$ & 5 & E & $\mathrm{P}$ & $\mathrm{N}$ & $\mathrm{N}$ & M & 16 & $6 \mathrm{~B}$ \\
\hline $310 \mathrm{C}$ & 6 & E & $\mathrm{P}$ & $\mathrm{N}$ & $\mathrm{N}$ & M & 16 & $6 \mathrm{~B}$ \\
\hline $369 \mathrm{~B}$ & 7 & E & Q & $\mathrm{O}$ & $\mathrm{O}$ & $\mathrm{N}$ & 17 & $6 \mathrm{~B}$ \\
\hline $369 \mathrm{C}$ & 8 & E & Q & $\mathrm{O}$ & $\mathrm{O}$ & $\mathrm{N}$ & 17 & $6 \mathrm{~B}$ \\
\hline $352 \mathrm{C}$ & 23 & $\mathrm{~F}$ & $\mathrm{R}$ & $\mathrm{N}$ & $\mathrm{P}$ & $\mathrm{O}$ & 18 & 1 \\
\hline $175 B$ & 1 & $\mathrm{G}$ & $\mathrm{S}$ & A & Q & $P$ & 19 & $6 \mathrm{~B}$ \\
\hline No. of types & & 7 & 19 & 15 & 17 & 16 & 19 & 10 \\
\hline
\end{tabular}

${ }^{a}$ The numbers in the strain designations represent different patients (022 to 175), and the letters indicate the clinical origin of the strain: blood (B) or CSF (C)

${ }^{b}$ Lanes as numbered in Fig. 1 to 5 .

${ }^{c} 16 \mathrm{~S}$, ribotyping; BOX, BOX fingerprinting; PCR, PCR fingerprinting; PFGE, pulsed-field gel electrophoresis.

${ }^{d}$ DNA types were determined by combining the results of the five fingerprint techniques. The DNA types shared by different strains are in boldface. The types $1 \mathrm{~A}$ and $1 \mathrm{~B}$ were found to differ from type 1 by only one technique.

The cutoff value of $95 \%$ similarity was used to classify identical and distinct strain types.

${ }^{f}$ The DNA was degraded.

Spanjaard, Academic Medical Center, Amsterdam, The Netherlands). This center is in charge of the collection of invasive pneumococcal isolates in The Netherlands. The isolates used in this study were randomly sampled from the 1992 collection. The strains were isolated from blood and/or cerebrospinal fluid (CSF) of 21 Dutch patients with meningitis and/or bacteremia. The patients originated from different parts of The Netherlands, and epidemiological relatedness was not assumed. Serotyping was performed by L. van Alphen (Academic Medical Center, Amsterdam, The Netherlands) on the basis of capsular swelling (quellung reaction) with type-specific antisera (Statens Serum Institute, Copenhagen, Denmark). The strains and serotypes are listed in Table 1. Pneumococci were grown on Columbia agar plates containing $5 \%$ defibrinated sheep blood or in Todd-Hewitt broth containing $0.5 \%$ yeast extract. Cultured isolates of Staphylococcus aureus; Staphylococcus warneri; Staphylococcus epidermidis; Streptococcus bovis; Enterococcus faecalis; group A, C, and F streptococci; Enterococcus durans; Enterococcus avium; Rhodococcus equi; Listeria monocytogenes; Bacillus circulans; corynebacteria; and nocardia were provided by A. van Belkum.

Chromosomal DNA extraction and restriction enzyme digestion. The bacterial cultures were grown to an optical density at $560 \mathrm{~nm}$ of 0.6 . The cells were harvested by centrifugation at $5,000 \times g$ for $10 \mathrm{~min}$. Genomic DNA was extracted either by the cetyl trimethylammonium bromide (CTAB) method (23) or in situ from pneumococci embedded in agarose (8). The restriction enzymes $P v u I I$ and EcoRI were used to digest the CTAB-purified chromosomal DNA samples (17). Agarose-embedded DNA was digested with ApaI (8).
DNA probes. The oligonucleotides BR-A (5'ATACTCTTCGAAAATCTCT TCAAAC), BR-B (5'ACAACCTCAAAACAGTGTTT), and BR-C (5'TATAC TCAATGAAAATCAAAGAGCA) were derived from the BOX repeat sequence of S. pneumoniae (10). The oligonucleotides CR-1 ([5'AGAGTTTGATC (AC)TGG(TC)TCAG] and CR-3 [5'CTTTACGCCCA(AG)T(AG)A(AT)TC CG], which correspond to positions 8 to 27 and 536 to 517 of the Escherichia coli 16S rRNA gene, respectively, were kindly provided by L. M. Schouls, National Institute of Public Health and Environmental Protection, Bilthoven, The Netherlands. Oligonucleotide BR-B was labeled with $\left[\tau-{ }^{33} \mathrm{P}\right]$ ATP (Amersham International plc, Little Chalfont, Bucks, United Kingdom) and used as a probe for Southern blot hybridization analysis. The oligonucleotide primer pairs BR-ABR-C and CR-1-CR-3 were used in PCR to generate the 151-bp BOX repeat sequence and the 536-bp 16S rRNA gene part, respectively. DNA amplification was performed by PCR as described previously (5). Both amplified DNAs were used to probe the Southern blots. The PCR-amplified probes were labeled with the enhanced chemiluminescence gene detection system (Amersham International plc) according to the recommendations of the manufacturer

Ribotyping and BOX fingerprinting. Purified chromosomal DNA of the $S$. pneumoniae strains was digested with the restriction enzyme $P v u \mathrm{II}$. Internal markers were added to the digested DNA samples according to the method described by van Soolingen et al. (23). The restriction fragments were separated electrophoretically on a $0.8 \%$ agarose gel, denatured, and transferred onto a nylon membrane (Hybond $\mathrm{N}+$; Amersham International plc) by vacuum blotting (VacuGene; Pharmacia LKB Biotechnology AB, Uppsala, Sweden). Hybridization analysis was performed with the 529-bp 16S rRNA gene probe. The blots were hybridized overnight at $42^{\circ} \mathrm{C}$ with hybridization buffer (Amersham International plc) supplemented with $\mathrm{NaCl}(0.5 \mathrm{M})$ and $200 \mathrm{ng}$ of labeled DNA probe. Washing was performed two times for $20 \mathrm{~min}$ at $42^{\circ} \mathrm{C}$ with wash buffer $(0.5 \times \mathrm{SSC}$ [1× SSC is $0.15 \mathrm{M} \mathrm{NaCl}$ plus $0.015 \mathrm{M}$ sodium citrate], $0.4 \%$ sodium dodecyl sulfate [SDS], $6 \mathrm{M}$ urea), and this was followed by washing at room temperature for 5 min with $2 \times$ SSC. Detection was carried out with the chemiluminescence gene detection system by procedures recommended by the manufacturer. The blots were rehybridized overnight with the radiolabeled BOX repeat oligonucleotide probe BR-B in $5 \times$ SSC containing $5 \times$ Denhardt solution, $5 \mathrm{mM}$ EDTA, $0.5 \%$ SDS, and $100 \mu \mathrm{g}$ of herring sperm DNA per $\mathrm{ml}$ (23). The membranes were washed twice for $30 \mathrm{~min}$ at $42^{\circ} \mathrm{C}$ with $2 \times$ SSC containing $0.1 \%$ SDS and were exposed for various times at $-70^{\circ} \mathrm{C}$ to $\mathrm{X}$-ray films (ECL-Hyperfilm; Amersham International plc)

PCR fingerprinting. The purified chromosomal $S$. pneumoniae DNA samples were subjected to PCR fingerprinting as described previously (22). The primer ERIC2 (5'AAGTAAGTGACTGGGGTGAGCG) (25) encoding the enterobacterial repetitive intergenic consensus sequence was used in PCR. The PCR program consisted of 40 cycles of consecutive denaturation $\left(1 \mathrm{~min}\right.$ at $94^{\circ} \mathrm{C}$ ), primer annealing $\left(1 \mathrm{~min}\right.$ at $\left.25^{\circ} \mathrm{C}\right)$, and DNA extension $\left(1 \mathrm{~min}\right.$ at $\left.74^{\circ} \mathrm{C}\right)$. The amplified products were electrophoretically separated on $2 \%$ agarose gels and stained with ethidium bromide.

Pulsed-field gel electrophoresis. The pulsed-field gel electrophoresis procedure was adapted from the procedure described by Lefevre et al. (8). The DNA macrorestriction fragments embedded in agarose were separated on a $1 \%$ agarose gel by pulsed-field gel electrophoresis (CHEF DRIII; Bio-Rad Laboratories Inc., Veenendaal, The Netherlands). Electrophoresis was performed for $22 \mathrm{~h}$ a $14^{\circ} \mathrm{C}$ at $6 \mathrm{~V} / \mathrm{cm}$ in $0.5 \times$ Tris-borate-EDTA (17) with pulse times of 2 to $30 \mathrm{~s}$ and an angle of $120^{\circ}$. Both the agarose gel and the electrophoresis buffer were supplied with $0.1 \mu \mathrm{g}$ of ethidium bromide per $\mathrm{ml}$.

Restriction fragment end labeling. Typing of the pneumococcal strains by restriction fragment end labeling was performed by the method of van Steenbergen et al. (24). Briefly, the purified pneumococcal DNA was digested with the restriction enzyme $E c o$ RI. The DNA restriction fragments were labeled at $72^{\circ} \mathrm{C}$ with $\left[\alpha{ }^{32} \mathrm{P}\right] \mathrm{dATP}$ by means of Taq DNA polymerase. The radiolabeled fragments were denatured and separated electrophoretically on a $6 \%$ polyacrylamide sequencing gel containing $8 \mathrm{M}$ urea. Subsequently, the gel was transferred onto filter paper, vacuum dried (Bio-Rad Laboratories Inc.), and exposed for various lengths of time at $-70^{\circ} \mathrm{C}$ to X-ray films (Fuji RX film; Fuji Medical Systems, Houten, The Netherlands).

Computer-assisted analysis of the DNA fingerprints. The ribotypes and BOX fingerprints were analyzed with the Windows version of Gelcompar software version 3.10 (Applied Maths, Kortrijk, Belgium) after the autoradiograms were imaged with a scanner at 190 dots per inch (HP Scanjet IIcx/T; Hewlett Packard, Amsterdam, The Netherlands). The mobilities of the DNA fragments hybridizing with the DNA probes were compared with those of a set of internal molecular weight markers by superimposing autoradiograms containing the DNA fingerprints and autoradiograms containing the internal markers of known molecular sizes (23). This procedure enabled us to normalize the position of each of the hybridizing fragments irrespective of autoradiogram and/or gel distortions. The fingerprints displayed by PCR and restriction fragment end labeling were normalized with pneumococcus-specific bands that were present in the fingerprints of all strains. The pulsed-field fingerprints were normalized with the molecular weight markers and the DNA bands of $S$. pneumoniae reference strain ATCC 6303 that were present on each gel. Comparison of the fingerprints produced by ribotyping, PCR fingerprinting, restriction fragment end labeling, and pulsedfield gel electrophoresis was performed by the UPGMA clustering method, with the Jaccard coefficient being applied to peaks. Comparison of the BOX finger- 
prints was performed according to the Pearson correlation coefficient with the continuous spectrum of the patterns. Computer-assisted analysis and the methods and algorithms used in this study were carried out according to the instructions of the manufacturer of Gelcompar. A tolerance in the band positions of $2 \%$ was applied during the comparison of the fingerprint patterns.

\section{RESULTS}

Genotyping of $S$. pneumoniae strains by various DNA fingerprint methods. (i) Ribotyping. Chromosomal $P v u$ II restriction fragments of 28 pneumococcal strains were separated by agarose gel electrophoresis and were subsequently analyzed by Southern blot hybridization. The DNA fingerprint results with the 529-bp 16S-rRNA gene probe are shown in Fig. 1A and B. The fingerprints were analyzed by computer comparison, and a dendrogram was calculated with the Jaccard algorithm (Fig. 1C). Seven distinct ribotypes were observed, and they consisted of two types which were uniquely present and five ribotype clusters of identical fingerprints found in 2 to 11 strains. The $S$. pneumoniae strains isolated from blood and CSF were invariably identical within a single individual. This is consistent with the assumption that a single $S$. pneumoniae strain is responsible for infection in these patients. The clustering of the pneumococcal strains observed by serotyping did not correlate with the genetic relatedness observed by ribotyping. Within clusters of identical ribotypes, different serotypes were found. Furthermore, strains with an identical serotype were spread over different ribotypes (Fig. 1C).

(ii) BOX fingerprinting. The same blots used above were rehybridized with oligonucleotide probe $\mathrm{BR}-\mathrm{B}$, which is homologous to the $\mathrm{B}$ part of the $\mathrm{BOX}$ repeat. The fingerprint results are shown in Fig. 2A and B. Because of the complexity of the banding patterns, computerized comparison of the 28 fingerprints was performed according to the method of Pearson (Fig. 2C). The observed polymorphism is strikingly higher in comparison with that of ribotyping. Twenty-one distinct fingerprint patterns were observed when a cutoff value of $95 \%$ similarity was used. Seven clusters of two strains sharing identical fingerprints were detected. Six out of seven clusters were blood and CSF isolates of individual patients. The blood and CSF strains isolated from patient 242 were only $75 \%$ similar. However, the blood isolate of this patient was strongly homologous (95\%) with the blood isolate of patient 353, although their serotypes were different. Rehybridization of the blots with the 151-bp BOX repeat probe containing the entire BOX sequence yielded DNA fingerprint patterns that were identical to those observed with the oligonucleotide probe BR-B (data not shown). Furthermore, the genetic relatedness observed by BOX fingerprinting did not correspond with the clustering based on serotyping (Fig. 2C).

The occurrence of $\mathrm{BOX}$ repetitive sequences in various other gram-positive species was investigated by Southern blot hybridization. So far, the presence of the BOX sequence is restricted to $S$. pneumoniae, as the BOX probes did not hybridize with chromosomal DNA from $S$. aureus; $S$. warneri; $S$. epidermidis; $S$. bovis; E. faecalis; group A, C, and F streptococci; E. durans; E. avium; R. equi; L. monocytogenes; B. circulans; corynebacteria; and nocardia (data not shown). These preliminary data suggest species specificity for this repetitive sequence.

(iii) PCR fingerprinting. The 28 pneumococcal DNA samples were also investigated by PCR fingerprinting with a single primer, ERIC2. The observed banding patterns, shown in Fig. 3A, were analyzed by the method of Jaccard (Fig. 3B). Nine clusters of identical PCR fingerprints representing two to five strains were observed. Six clusters contained blood and CSF isolates of individual patients. Similar to the BOX fingerprint
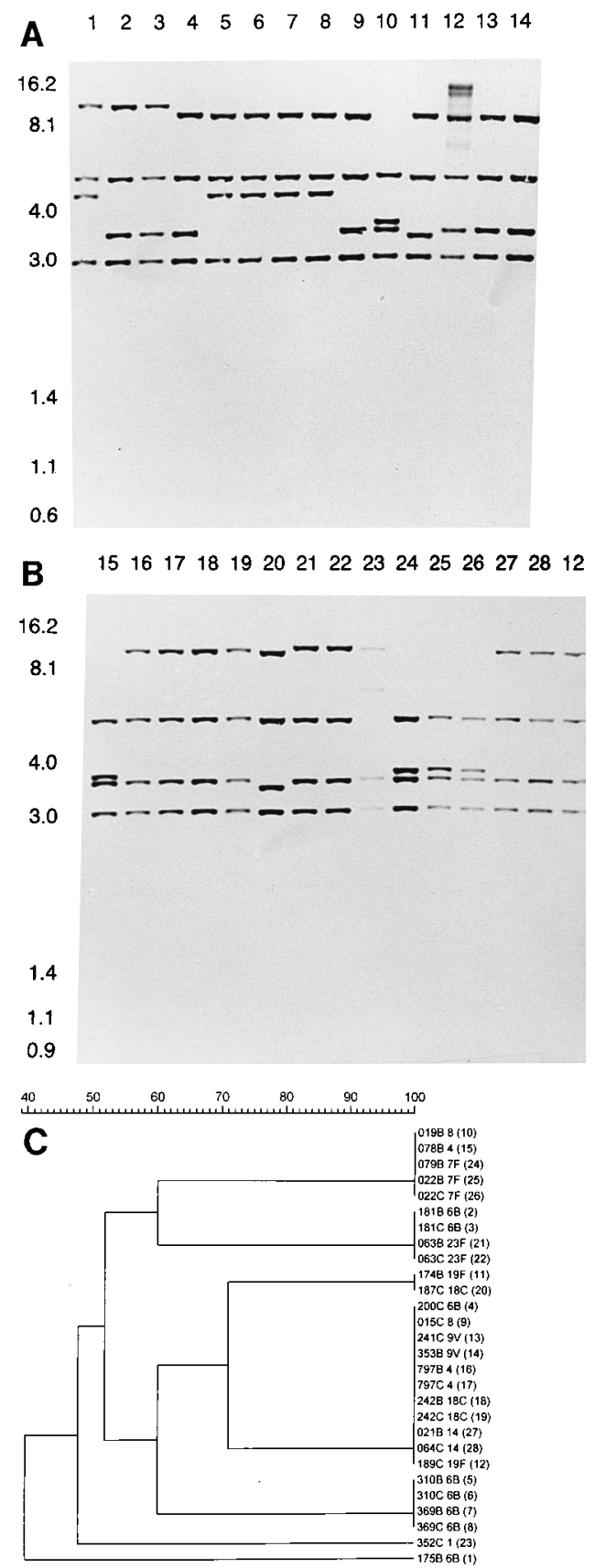

FIG. 1. DNA fingerprint analysis of $28 \mathrm{~S}$. pneumoniae strains by ribotyping (A and $\mathrm{B}$ ) and dendrogram of the fingerprints as determined by the Jaccard method (C). In panel C, the scale measures similarity values, and the codes at the right give the strain number according to Table 1, serotype, and lane number (in parentheses) of the strain in panel A or B. Because of partial DNA restriction of strain $189 \mathrm{C}$ in panel A (lane 12), the fingerprint analysis was repeated in panel $B$. The numbers at the left in panels A and B indicate the sizes of standard DNA fragments in kilobase pairs.

analysis, the PCR fingerprint patterns of the blood and CSF isolates from patient 242 were distinct and formed a genetically related group with strains $241 \mathrm{C}$ and $353 \mathrm{~B}$. Furthermore, the genetic relatedness observed by PCR fingerprinting did not correspond with the clustering based on serotyping (Fig. 3B).

(iv) Pulsed-field gel electrophoresis. Large chromosomal restriction fragments of the 28 pneumococcal strains were sepa- 

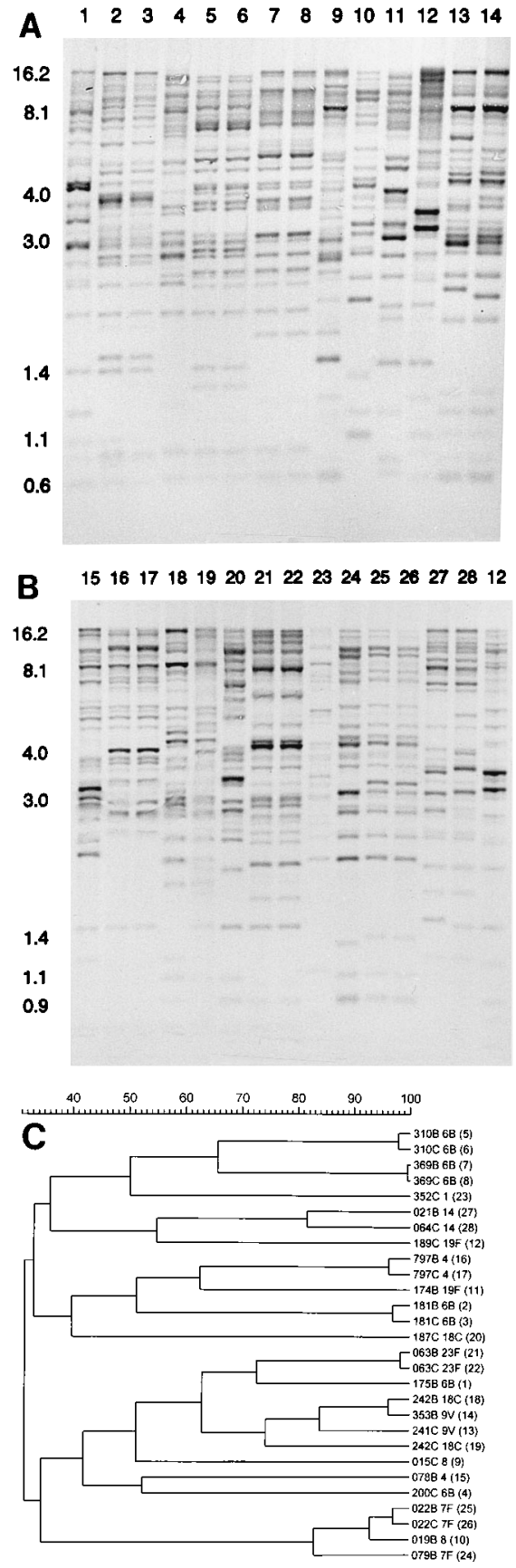

FIG. 2. RFLP analysis of 28 S. pneumoniae strains by BOX fingerprinting (A and $\mathrm{B}$ ) and dendrogram of the fingerprints as determined by the Pearson method (C). In panel C, the scale measures similarity values, and the codes at the right give the strain number according to Table 1, serotype, and lane number (in parentheses) of the strain in panel A or B. Because of partial DNA restriction of strain 189C in panel A (lane 12), the fingerprint analysis was repeated in panel $\mathrm{B}$. The numbers at the left in panels A and B indicate the sizes of standard DNA fragments in kilobase pairs.

rated by pulsed-field gel electrophoresis. The molecular sizes of the ApaI fragments ranged from $20 \mathrm{~kb}$ to $290 \mathrm{~kb}$, as can be seen in Fig. 4A and B. Because of DNA degradation, strain 021B was excluded from computerized analysis. Among the 27 strains, 19 distinct fingerprint types were observed by the Jaccard analysis (Fig. 4C). Seven clusters of identical fingerprints

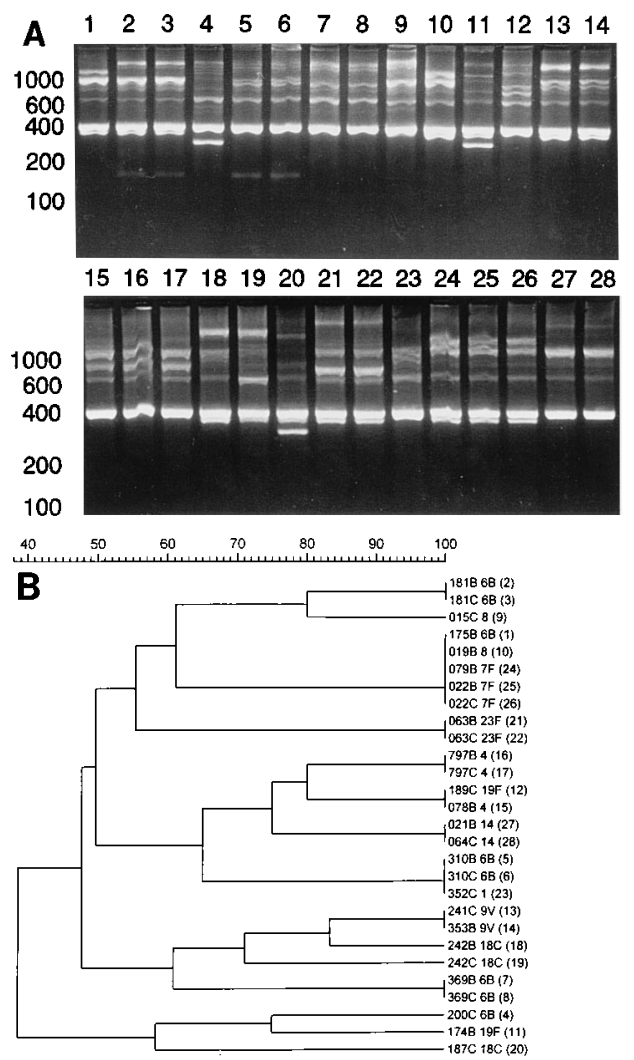

FIG. 3. PCR fingerprint analysis of $28 S$. pneumoniae strains (A) and dendrogram of the fingerprints as determined by the Jaccard method (B). In pane $\mathrm{B}$, the scale measures similarity values, and the codes at the right give the strain number according to Table 1, serotype, and lane number (in parentheses) of the strain in panel A. The numbers at the left of panel A indicate the sizes of standard DNA fragments in base pairs.

representing two to four strains were observed. The $S$. pneumoniae strains isolated from blood and CSF of individual patients invariably yielded identical fingerprints. By this technique, the pneumococcal isolates 242B, 242L, and 353B were identical, and in agreement with the results of BOX and PCR fingerprinting, $241 \mathrm{C}$ was genetically strongly related. Furthermore, in a result similar to one of ribotyping, the pneumococcal strains isolated from the blood of patients 019 and 079 displayed fingerprints identical to those of the blood and CSF isolates of patient 022 . The clustering of the strains according to serotyping did not correlate with the genetic relatedness observed by pulsed-field gel electrophoresis (Fig. 4C).

(v) Restriction fragment end labeling. The small EcoRI fragments of the 28 pneumococcal isolates were exploited for fingerprint purposes. The RFLP among these strains in the molecular size range of 200 to 430 bases was analyzed by restriction fragment end labeling. The fingerprint patterns are shown in Fig. 5A. Seventeen distinct fingerprints were found by a computerized comparison conducted according to the method of Jaccard (Fig. 5B). Eight clusters of identical fingerprints were observed, representing from two to four strains. Six out of seven pairs of blood and CSF isolates showed identical fingerprints. The $S$. pneumoniae strains isolated from the blood and CSF of patient 242 were genetically clustered but revealed distinct fingerprint patterns. In a result similar to those of BOX fingerprinting, PCR fingerprinting, and pulsed-field gel electrophoresis, the degree of similarity of the end-labeling patterns of the blood isolates of patients 242 and 353 was higher 


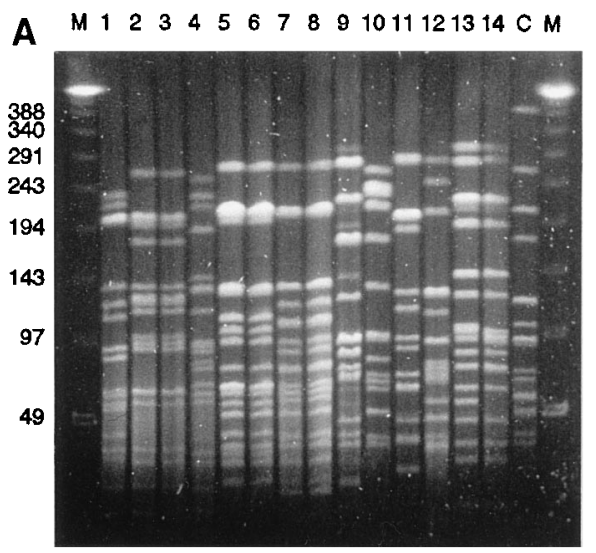

B M 1516171819202122232425262728 C M
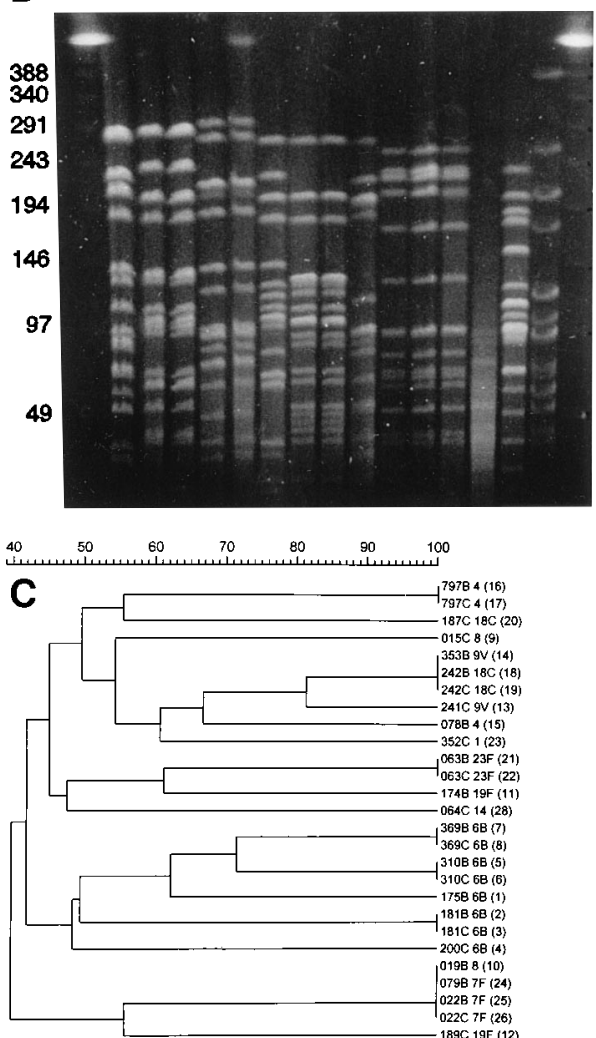

FIG. 4. RFLP analysis of $28 \mathrm{~S}$. pneumoniae strains by pulsed-field gel electrophoresis (A and B) and dendrogram of the fingerprints as determined by the Jaccard method (C). Because of DNA degradation, strain 021B (panel B, lane 27) was excluded from computerized analysis. In panel $\mathrm{C}$, the scale measures similarity values, and the codes at the right give the strain number according to Table 1, serotype, and lane number (in parentheses) of the strain in panel A or B. Lanes C (A and B) represent ApaI-restricted chromosomal DNA of reference strain ATCC 6303. The numbers at the left of panels A and B indicate the sizes of standard DNA fragments (lanes M) in kilobase pairs.

by comparison with the degree of similarity between the blood and CSF isolates of patient 242 . The clustering by serotyping of the strains did not correlate with the genetic relatedness observed by restriction fragment end labeling (Fig. 5B).

Comparison of the various DNA typing methods. (i) Ease of use and interpretation. All five DNA fingerprint methods required culture of the pneumococcal strains and chemical and enzymatic treatment of the cells to obtain chromosomal DNA.

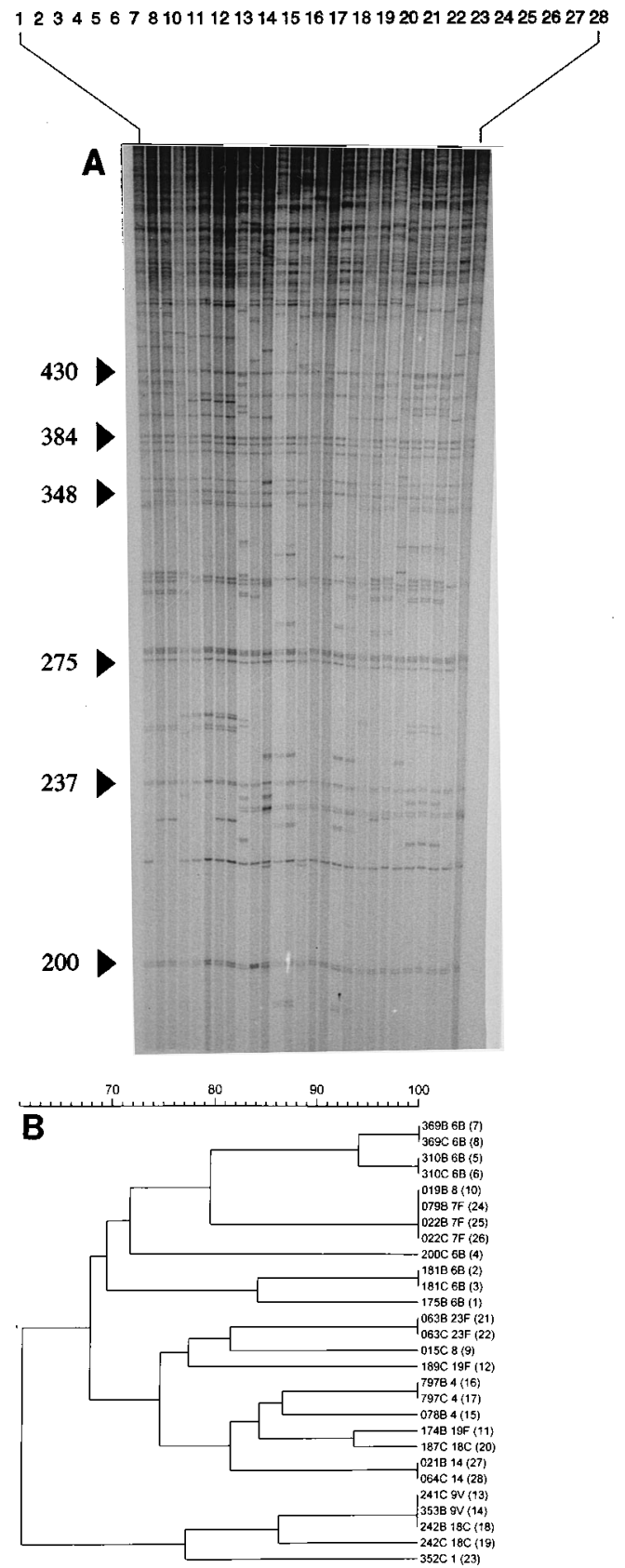

FIG. 5. DNA fingerprint analysis of 27 S. pneumoniae strains by restriction fragment end labeling (A) and dendrogram of the fingerprints as determined by the Jaccard method (B). Although strain $015 \mathrm{C}$ is absent from panel A, its fingerprint (data not shown) is included in the computerized comparison (B). In panel $\mathrm{B}$, the scale measures similarity values, and the codes at the right give the strain number according to Table 1 , serotype, and lane number (in parentheses) of the strain in panel A. The arrowheads in panel A indicate the pneumococcusspecific DNA fragments which were used for normalization. The numbers at the left of panel A indicate the sizes of standard single-strand DNA fragments in bases.

PCR fingerprinting was performed most rapidly. Within 1 day, the PCR was carried out, and the fingerprints were realized by separating the amplified products electrophoretically. Restriction fragment end labeling was also easy to perform. The chromosomal DNA samples were enzymatically digested, radiolabeled, and separated electrophoretically within a day, and 
they were exposed overnight to an X-ray film. Ribotyping and BOX fingerprinting required 3 days because of the time needed for DNA digestion, electrophoretic separation of the restriction fragments, transfer of the DNA onto filter membranes, probe hybridization and detection, and rehybridization of the blots with the internal marker probe. Pulsed-field gel electrophoresis was also a laborious and time-consuming technique because of the need for extensive treatment of the agarose-embedded cells and the limited throughput of samples per gel.

The ease with which computerized analysis of the fingerprints can be performed also differed significantly among the various techniques. DNA bands which can serve as internal markers to normalize the banding patterns are important for an accurate analysis. Because of the lack of a sufficient number of DNA bands that are commonly present in all pneumococcal strains, both PCR fingerprinting and pulsed-field gel electrophoresis were poorly suited for computerized comparisons. Since the ribotype and BOX fingerprint patterns had internal markers mixed in, adjustment for computerized analysis was very easy to perform. The pneumococcus-specific restriction fragments which occur in all DNA samples subjected to restriction fragment end labeling (Fig. 5A) were also very suitable for normalization of the banding patterns.

(ii) Discriminatory power. The genetic clusters of identical fingerprints as observed by the five different DNA typing methods are summarized in Table 1 . The discriminatory power of the five DNA fingerprint techniques ranged from 7 types by ribotyping to 19 types by BOX fingerprinting. As shown in Fig. 1 to 5 , the similarity values also ranged significantly among the techniques, varying from 35 to $99 \%$ for BOX fingerprinting to 63 to $100 \%$ for restriction fragment end labeling. However, a comparison of the genetic clustering of the 28 strains showed a high degree of resemblance. Except for patient 242, the fingerprints of blood and CSF isolates within individual patients were identical by all techniques. For the blood and CSF isolates of patient 242, BOX fingerprinting, restriction fragment end labeling, and PCR fingerprinting revealed a group, genetically strongly related but with distinct banding patterns. The blood isolate from patient 353 and the CSF isolate from patient 241 are invariably clustered with the blood and CSF isolates of patient 242. Genetic clustering of the isolates from patients 019,079 , and 022 was also invariably present in all fingerprint techniques. Finally, except for PCR fingerprinting, the techniques disclosed grouping of the blood and CSF isolates from patients 310 and 369 .

\section{DISCUSSION}

The aim of the present study was to identify the strengths and weaknesses of various DNA typing methods for $S$. pneumoniae so that the methods best suited for application in clinical and research microbiology laboratories could be determined. To this purpose, five different fingerprint techniques were performed in our laboratory to investigate the genetic relatedness of $28 \mathrm{~S}$. pneumoniae strains isolated from the blood and/or CSF of 21 different patients (Table 1). The number of strongly related fingerprints (similarity values of $\geq 95 \%$ ) varied among the different techniques. Ribotyping resulted in 7 distinct fingerprint patterns (Fig. 1), whereas the other techniques yielded 14 to 19 distinct patterns (Fig. 2 to 5). These data suggest that the evolutionary clock displayed by ribotyping is running very slow. Furthermore, 11 of 28 strains belonged to a single ribotype pattern, suggesting the clonal relatedness of these strains. We conclude that ribotyping is a useful technique to investigate long-term epidemiological events, such as the genetic relatedness among pneumococcal strains from geographically distinct sources.

Although the discriminatory powers and the similarity values of the strains ranged significantly among the different techniques, a comparison of the genetic clustering of the 28 strains showed a high degree of resemblance. Except for patient 242, blood and CSF isolates within individual patients were invariably identical. This result is consistent with infection with a single pneumococcal strain. Moreover, the blood isolate from patient 353 and the CSF isolate from patient 241 are invariably clustered with the blood and CSF isolates of patient 242. Interestingly, by $\mathrm{BOX}$ fingerprinting, PCR fingerprinting, and restriction fragment end labeling, the pneumococcal strains $241 \mathrm{C}$ and $353 \mathrm{~B}$ were genetically more related to the blood isolate of patient 242 than was the CSF isolate of the same patient. Since the serotypes of the blood and CSF isolates from patient 242 were identical (18C) and differed from those of isolates $241 \mathrm{C}(\mathrm{gV})$ and $353 \mathrm{~B}(\mathrm{gV})$, we assume that this patient was infected with a single pneumococcal strain which genetically diverged either during infection or during culture in the laboratory. The five techniques also invariably displayed the clustering of the isolates from patients 019, 079, and 022. Finally, with the exception of PCR fingerprinting, the techniques demonstrated genetic clustering of blood and CSF isolates from patients 310 and 369. In summary, we conclude that the determinations of the genetic clustering of the pneumococcal strains by the individual fingerprint methods are comparable.

Two methods described in this study, ribotyping and BOX fingerprinting, make use of DNA probes to determine RFLP among pneumococcal strains. The method of Southern blot hybridization analysis is widely used by molecular epidemiologists. We have performed the protocol developed by van Soolingen et al. (23) in which each DNA sample is mixed with molecular-size DNA markers to adjust for differences among samples. This method has been suitable for accurate comparisons of large numbers of Mycobacterium tuberculosis IS6110 fingerprints. Because of the internal markers, the computerassisted comparisons of both the ribotype and the BOX fingerprints were very easy to perform. We conclude that both techniques are very suitable for the analysis of large collections of pneumococcal strains. In contrast to the limitations of ribotyping, the discriminatory potential of BOX fingerprinting was extremely high, since 21 of 28 strains showed less than $95 \%$ similarity. The BOX repeat sequence can be used to type only $S$. pneumoniae strains, since the probe did not hybridize with chromosomal DNA from 15 other gram-positive species.

PCR fingerprinting is an easy and quick method which is suitable to investigate the genetic relatedness of pneumococcal strains. Initially, computerized analysis of the fingerprints was performed according to the Pearson correlation coefficient. This algorithm considers both the number of bands and band intensity. However, since the presence of the amplified band of $400 \mathrm{bp}$ is highly predominant for all isolates, analysis of the PCR banding patterns with the Pearson correlation coefficient was entirely overruled by this band, resulting in the presence of a single cluster of highly homologous fingerprints (unpublished observations). Therefore, we have analyzed the PCR fingerprints by the UPGMA clustering method, applying the Jaccard coefficient to peaks. By this method, only band positions are considered regardless their relative intensities. The genetic clustering observed by PCR fingerprinting matched with that determined by other DNA typing methods. However, the computerized analysis of PCR fingerprints was difficult to perform because of the lack of sufficient numbers of pneumococcusspecific bands which can serve as internal markers to normalize the PCR banding patterns. Furthermore, the difficulties in the 
reproducibility of the technique reported by many investigators may cause problems in the generation of reliable PCR fingerprint libraries (for a review, see reference 22). Nevertheless, since PCR fingerprinting is an easy and quick method, we conclude that this technique is of potential use for the rapid analysis of relatively small numbers of strains.

Pulsed-field gel electrophoresis and restriction fragment end labeling detect RFLP of large and small restriction fragments, respectively. As expected, the discriminatory powers of both methods were comparable. However, the suitability of these techniques for computer-assisted analysis differed significantly. Comparison of the pulsed-field patterns present on two different gels was complicated because of the lack of pneumococcal reference bands. Furthermore, pulsed-field gel electrophoresis is a laborious and time-consuming technique because of the need for extensive treatment of the agarose-embedded cells and the limited throughput of samples per gel. In contrast to pulsed-field gel electrophoresis, the end labeling method had pneumococcus-specific reference bands present in the fingerprints (Fig. 5). This greatly facilitated the computer-assisted analysis and allows computer-assisted analysis of large collections of fingerprints.

The genetic relatedness observed by the five genotypic methods did not correspond with the clustering of the strains by serotyping. This may be due to the phenotypical variation detected by serotyping, which is not related to the genetic variation displayed by the DNA fingerprint methods.

In summary, although the discriminatory powers of the five DNA fingerprint techniques differed significantly, the deduced genetic clusterings of the pneumococcal strains were comparable. The ease with which computerized analysis could be performed and the potential to create reliable fingerprint libraries differed significantly among the methods. Ribotyping and BOX fingerprinting were very suitable for computerized analysis of the fingerprints because of the presence of internal markers. Restriction fragment end labeling was also very suitable for normalization and computerized comparison of the banding patterns, since pneumococcus-specific restriction fragments were present in all DNA samples. Ribotyping, BOX fingerprinting, and restriction fragment end labeling are currently routinely used in our laboratory to generate international data libraries of pneumococcal fingerprints. A disadvantage of restriction fragment end labeling is the requirement for radiolabeled DNA. Currently, we are investigating the possibility of using nonradioactive labeling techniques in this assay.

Recently, DNA fingerprints from strains isolated in Poland were compared with the Dutch fingerprints present in our data libraries. Preliminary results have demonstrated that patterns from the Polish isolates represent a genetically distinct group which does not match with that of the Dutch isolates. This suggests an association between fingerprint types and geographic origin (4a).

\section{REFERENCES}

1. Cherian, T., M. C. Steinhoff, L. H. Harrison, D. Rohn, L. K. McDougal, and J. Dick. 1994. A cluster of invasive pneumococcal disease in young children in child care. JAMA 271:695-697.

2. Dowson, C. G., A. Hutchison, J. A. Brannigan, R. C. George, D. Hansman, J. Linares, A. Tomasz, J. M. Smith, and B. G. Spratt. 1989. Horizontal transfer of penicillin-binding protein genes in penicillin-resistant isolates of Streptococcus pneumoniae. Proc. Natl. Acad. Sci. USA 86:8842-8846.

3. Fenoll, A., C. M. Bourgon, R. Munoz, D. Vicioso, and J. Casal. 1991. Serotype distribution and antimicrobial resistance of Streptococcus pneumoniae isolates causing systemic infections in Spain, 1979-1988. Rev. Infect. Dis. 13:56-60.
4. Finland, M. 1982. Pneumococcal infections, p. 417-433. In A. S. Evans and H. A. Feldman (ed.), Bacterial infections of humans. Plenum Medical Book Company, New York.

4a.Hermans, P. W. M. Unpublished data.

5. Hermans, P. W. M., D. van Soolingen, E. M. Bik, P. E. W. de Haas, J. W. Dale, and J. D. A. van Embden. 1991. The insertion element IS987 from Mycobacterium bovis BCG is located in a hot-spot integration region for insertion elements in Mycobacterium tuberculosis complex strains. Infect. Immun. 59:2695-2705.

6. Kell, C. M., J. Z. Jordens, M. Daniels, T. J. Coffey, J. Bates, J. Paul, C. Gilks, and B. G. Spratt. 1993. Molecular epidemiology of penicillin-resistant pneumococci isolated in Nairobi, Kenya. Infect. Immun. 61:4382-4391.

7. Kristinsson, K. G., M. A. Hjalmarsdottir, and O. Steingrimsson. 1992. Increasing penicillin resistance in pneumococci in Iceland. Lancet 339:16061607.

8. Lefevre, J. C., G. Faucon, A. M. Sicard, and A. M. Gasc. 1993. DNA fingerprinting of Streptococcus pneumoniae strains by pulsed-field gel electrophoresis. J. Clin. Microbiol. 31:2724-2728.

9. Lund, E., and J. Henrichsen. 1978. Laboratory diagnosis, serology and epidemiology of Streptococcus pneumoniae, p. 241-262. In T. Bergan and J. R. Norris (ed.), Methods in microbiology, vol. 12. Academic Press, New York.

10. Martin, B., O. Humbert, M. Camara, E. Guenzi, J. Walker, T. Mitchell, P. Andrew, M. Prudhomme, G. Alloing, R. Hakenbeck, D. A. Morrison, G. J. Boulnois, and J.-P. Claverys. 1992. A highly conserved repeated DNA element located in the chromosome of Streptococcus pneumoniae. Nucleic Acids Res. 20:3479-3483.

11. Marton, A., M. Gulyas, R. Munoz, and A. Tomasz. 1991. Extremely high incidence of antibiotic resistance in clinical isolates of Streptococcus pneumoniae in Hungary. J. Infect. Dis. 163:542-548.

12. McDougal, L. K., R. Facklam, M. Reeves, S. Hunter, J. M. Swenson, B. C. Hill, and F. C. Tenover. 1992. Analysis of multiply antimicrobial-resistant isolates of Streptococcus pneumoniae from the United States. Antimicrob. Agents Chemother. 36:2176-2184.

13. Munoz, R., T. J. Coffey, M. Daniels, C. G. Dowson, G. Laible, J. Casal, R. Hakenbeck, M. Jacobs, J. M. Musser, B. G. Spratt, and A. Tomasz. 1991. Intercontinental spread of a multiresistant clone of serotype 23F Streptococcus pneumoniae. J. Infect. Dis. 164:302-306.

14. Munoz, R., C. G. Dowson, M. Daniels, T. J. Coffey, C. Martin, R. Hakenbeck, and B. G. Spratt. 1992. Genetics of resistance to third-generation cephalosporins in clinical isolates of Streptococcus pneumoniae. Mol. Microbiol. 6:2461-2465.

15. Munoz, R., J. M. Musser, M. Crain, D. E. Briles, A. Marton, A. J. Parkinson, U. Sorensen, and A. Tomasz. 1992. Geographic distribution of penicillinresistant clones of Streptococcus pneumoniae: characterization by penicillinbinding protein profile, surface protein A typing, and multilocus enzyme analysis. Clin. Infect. Dis. 15:112-118.

16. Nielsen, S. V., and J. Henrichsen. 1993. Capsular types and susceptibility to penicillin of pneumococci isolated from cerebrospinal fluid or blood in Denmark, 1983-1988. Scand. J. Infect. Dis. 25:165-170.

17. Sambrook, J., E. F. Fritsch, and T. Maniatis. 1989. Molecular cloning: a laboratory manual, 2nd ed. Cold Spring Harbor Laboratory Press, Cold Spring Harbor, N.Y.

18. Sessegolo, J. F., A. S. S. Levin, C. E. Levy, M. Asensi, R. R. Facklam, and L. M. Teixeira. 1994. Distribution of serotypes and antimicrobial resistance of Streptococcus pneumoniae strains isolated in Brazil from 1988 to 1992. J. Clin. Microbiol. 32:906-911.

19. Shapiro, E. D., and R. Austrian. 1994. Serotypes responsible for invasive Streptococcus pneumoniae infections among children in Connecticut. J. Infect. Dis. 169:212-214.

20. Smith, A. M., K. P. Klugman, T. J. Coffey, and B. G. Spratt. 1993. Genetic diversity of penicillin-binding protein 2B and 2X genes from Streptococcus pneumoniae in South Africa. Antimicrob. Agents Chemother. 37:1938-1944.

21. Soares, S., K. G. Kristinsson, J. M. Musser, and A. Tomasz. 1993. Evidence for the introduction of a multiresistant clone of serotype 6B Streptococcus pneumoniae from Spain to Iceland in the late 1980s. J. Infect. Dis. 168:158-163.

22. van Belkum, A. 1994. DNA fingerprinting of medically important microorganisms by use of PCR. Clin. Microbiol. Rev. 7:174-184.

23. van Soolingen, D., P. E. W. de Haas, P. W. M. Hermans, and J. D. A. van Embden. 1993. DNA fingerprinting of Mycobacterium tuberculosis. Methods Enzymol. 235:196-205.

24. van Steenbergen, T. J. M., S. D. Colloms, P. W. M. Hermans, J. de Graaff, and R. H. A. Plasterk. Genomic DNA fingerprinting by restriction fragment end labelling. Submitted for publication.

25. Versalovic, J., T. Koeuth, and J. R. Lupski. 1991. Distribution of repetitive DNA sequences in eubacteria and application to fingerprinting bacterial genomes. Nucleic Acids Res. 19:6823-6831. 